\title{
The Concept of Development of the Tourism Industry under the Present System of Taxation
}

\author{
M. M. Kachurina ${ }^{1}$, A. V. Sharkova ${ }^{3}$, E. E. Konovalova ${ }^{1}$, N. V. Gubanova ${ }^{1,2} \&$ S. L. Razumovskiy ${ }^{1}$ \\ ${ }^{1}$ Federal Budgetary Establishment of Higher Professional Education «Russian State University of Tourism and \\ Service», Russian Federation \\ ${ }^{2}$ NOU VPO "Moscow Institute of State and Corporate Governance" (IRSG), Moscow, Russian Federation \\ ${ }^{3}$ Federal State-Funded Educational Institution of Higher Professional Education "Financial University under the \\ Government of the Russian Federation", Moscow, Russian Federation \\ Correspondence: M. M. Kachurina, Federal Budgetary Establishment of Higher Professional Education «Russian \\ State University of Tourism and Service», Pushkinskij r-n, 141221, pos. Cherkizovo, ul. Glavnaja, 99, Russian \\ Federation.
}

\author{
Received: October 4, 2014 Accepted: October 16, 2014 Online Published: December 2, 2014 \\ doi:10.5539/ass.v11n1p268 URL: http://dx.doi.org/10.5539/ass.v11n1p268
}

\begin{abstract}
The main objective of the tax system, which reflects the general patterns formed in this area, and features a specific country, industry and service tax is a positive impact on the expansion of certain types of activities, and therefore spheres of business activity and the development of the whole economy. The purpose of this article to review the main trends in the development of the tourism industry under the present system of taxation.
\end{abstract}

Keywords: tourism industry, taxation, taxation regimes, the concept of development

\section{Introduction}

The structure of international trade in services is quite complicated. However, that tourism has the greatest value. In value terms, there is an absolute increase in tourism and transport, while at the same time, the share of services in total exports of services is reduced. According to many experts, the effect of reducing sales to continue in the long term, as governments carry out the fight with the state budget deficit by raising taxes. Tourism market is a highly competitive market with opportunities consumer choice among several directions (high elasticity of demand). Therefore, this sector is particularly sensitive to tax policy. (Karmanova 2012; Kryukova \& Sokolova, 2014)

Being an export-oriented area, tourism exhibits greater stability compared with other activities in an unstable situation on world markets. Historically, after the reduction of income from tourism activities as a result of the impact of negative externalities almost immediately followed an increase in tourist arrivals. Therefore, in foreign countries tourist activity that has traditionally evolved in low taxation and has a high tax potential, has become an important field of activity of the fiscal authorities. (Kanin \& Kaurova, 2012)

In the next decade, the tax system in Russia will face tremendous challenges, which are caused by the need to adapt to the process of aging and optimizing the tax burden on the economy due to lower rental revenues in the medium term. In 2013, the first time in ten years, high oil prices have ceased to be the basis for economic growth. Under these conditions, taxes and their structure are essential components of structural reforms (along with the regulation of the labor market and employment promotion programs), as are the main source of state revenue. Therefore, great importance is the search for ways to optimize the tax burden. (Kryukova et al., 2014)

\section{Methods}

Need for a comprehensive analysis of the processes occurring in the system of taxation, led to extensive use of various specific and general scientific research methods. In particular, in this paper we use scientific methods such as scientific methods as a systematic approach, abstract and logical analysis, economic analysis and synthesis, dynamic and comparative analysis of statistical data, the method of economic groups, factor analysis method and expert evaluations. 
Information base amounted to legal acts in the field of taxation; data from the Federal Statistics Agency of the Russian Federation, the Russian Central Bank, Ministry of Finance; database of international economic organizations (the World Tourism Organization, the World Bank, the Organization for Economic Cooperation and Development, the International Monetary Fund and others.) results of empirical studies of domestic and foreign authors, publications in specialized journals and the media, Internet resources. (Lennon, 2008)

The study of a modern system of taxation of tourist activity is based on the author's approach to assessing the effects of changes in the taxation of tourist activity, based on the concept of limiting excessive tax burden, which allows us to estimate the difference between the growth of budget revenues and a loss of social welfare as a result of changes in taxation, taking into account the relationship of the tourism sector to other sectors of the economy.

\section{Results}

Summarizing the results of the study, we present the main conclusions of the study.

Taxation of tourist activities related to three features of the tourism industry, as reflected in the theoretical aspects:

- Internalization of external effects from tourists;

- The completion of the state budget revenues;

- The cost of production of public goods (such as higher costs for security due to the involvement of tourists).

In our opinion, all forms of tourism can be represented in the form of distribution for two reasons: the type of tourism product (from the standard product is exclusive) and the level of economic integration (low to high).

Features of tourist activity on the demand side and the supply side determines its intensive taxation.

At the moment there are four systems of taxation of business:

- The traditional tax system (Chap. 23 of the Tax Code 01.01., 2001);

- The simplified tax system (Chap. 26.3. H. 2 of the Tax Code FZ-104 from 24.07.2002, with the 01.01.2003);

- Imputation system (Chap. 26.3. H. 2 of the Tax Code FZ-104 from 24.07.2002, with the 01.01.2003);

- For agricultural producers (Chap. 26.1 of the Tax Code FZ-147 of 11.11. 2003 from 01.01.2004).

No optimality taxation in Russia determined by the violation of two basic principles: economy and efficiency. In the period 2009-2011. an average of $62 \%$ of the total income tax collected from companies with hotels and restaurants accounted for Moscow, 6\% - St. Petersburg, 13\% - in the Moscow region. Calculations factor VAT collection (figure savings) show that the gap in 2011 is two times lower than in 2012. The tax burden with a specific activity of tourism enterprises is not only growing (in 2011 hotels and restaurants - $12.5 \%$, activities, recreation and entertainment, culture and sport $-26.3 \%$ ), but ahead of the dynamics of the indicator in the tourism-related industries (for example, advocates trade - 2.4\%). (Kaurova et al., 2013; Borodin, 2010)

As a result, the tourism industry is not characterized by stable and inefficient development. Not determined by the stability of the growing number of enterprises in the industry. Inefficiency - the growth of unprofitable enterprises. By 2010, the share of unprofitable enterprises in the tourism sector has exceeded the share of loss-making enterprises in the Russian average.

\section{Discussion}

\subsection{Trends in the Development of Tourism in the Russian Federation (Kaurova et al., 2014)}

Most significantly affected by the crisis hotels. Sales volumes in 2009 fell by $15.8 \%$, significantly higher than the GDP fell (by 1.1\%). The financial crisis led to a reduction in demand for hotels, especially in the segment of business services. In the medium term is expected to increase demand for hotels, however, only in 2013 the growth rate of sales of hotels caught up with real GDP growth.

In the Russian Federation in the Concept of Long-Economic Development of the Russian Federation for the period until 2020 (Decree of the Russian Government on 17 November 2008 №1662-p) tourism is seen as an essential component of the innovative development of our country in the long term, cost-effective and environmentally friendly branch of the national economy.

Despite the fact that the tourist potential of Russia is used by only $20 \%$, the prospects for the development of tourism in our country are enormous. This is clearly seen on the basis of the targets of the Strategy of tourism development in the Russian Federation up to 2015 
Currently, the subjects of the Russian Federation implemented 65 regional programs for tourism development in 5 regions adopted the concept of tourism development. Funding for regional tourism development programs provided at the expense of subjects of the Russian Federation and extra budgetary sources and amounts according to preliminary estimates about 37 billion. Rubles, including extra-budgetary sources about 32 billion. Rubles, which is almost $85 \%$ of the total. First of all, extra-budgetary funds will be used for the construction of accommodation facilities in the regions. Undoubtedly, the economic crisis has affected the implementation of regional programs for tourism development. In many regions, funding for reduced (by an average of $15 \%$ ). However, there are positive examples. So, on December 31, 2008 in the Republic of Tatarstan adopted a republican target program "Development of tourism in the Republic of Tatarstan for 2009-2011", in which one of the republic's budget for tourism development was provided funding of \$ 224 million. rubles.

Tourism development in Russia in the years 2011-2016 it is planned to allocate 96 billion. Rubles on the basis of the adopted Concept of the federal target program "Development of domestic tourism in the Russian Federation (2011 - 2016)", adopted in 2010

\subsection{Transformation (Formation) in Tourism Products}

At the macro level components of gross value added (GVA) are the main articles of primary incomes of economic agents, and the elements of the final product - expenditure on final consumption and accumulation.

Therefore Relationship modeling elements GVA and the final product is proposed as the problem of describing the process of transformation of primary income in the final costs and savings. Transformation of income expenditure is mediated by a complex process of redistribution of financial resources among the institutional sectors, which must be taken into account.

Modelling of these bonds makes the problem of consistency of final expenditures with revenues of economic agents. Analysis of the consistency of income and expenses is especially necessary to develop scenarios of macroeconomic policies of the government and monitor the impact of the latter on the various sectors of the Russian economy. In addition, such an analysis is crucial in modeling and predicting the structure of final demand, as it allows "dock" it predetermined (via projection or scriptwriting) the structure of the financial results of production.

In Russia, the concept of the tourist industry came in 1996 with the adoption of the Federal Law "On the basis of tourist activity in the Russian Federation." The tourist industry - a collection of hotels and other accommodation facilities, vehicles, objects, educational, business, health, sports and other purposes, organizations engaged in the tour operator and travel agency activities, as well as organizations that provide services and tour guide service. Thus, this definition is also used by the demand approach. This approach provided an opportunity for tax purposes to consider these activities in a single legal field.

However, he determined the direction and tools to support the development of tourism on the demand side. For example, in Russia the majority of support from the tax system aimed at supporting consumers, for example, the creation of a tax instrument to support social tourism (children, youth, the elderly, and others.) By putting into practice the tourist activity of the social tax deduction on income from natural parties upon payment of the cost of travel within the territory of the Russian Federation.

Existing lists of tourist activities and products have important theoretical and practical significance, though not allow properly introduce tourism in the basic forms of statistical reporting, to assess the true extent of its economic potential.

In our opinion, all forms of tourism can be represented in the form of distribution for two reasons: the type of tourism product (from the standard product is exclusive) and the level of economic integration (low to high).

Type of product is determined by the presence of certain attributes which characterize its homogeneity. Degree of economic integration determines the level of cooperation between the national economy with the global .

In addition to the civil legislation of the tourist activities are regulated by the Federal Law of 24.11.96, № 132-FZ "On the basis of tourist activity in the Russian Federation", the Law of the Russian Federation from 07.02.92 № 2300-1 «On Protection of Consumers' Rights and Administrative (procedure for obtaining visas), currency (types of calculations), customs (border crossing rules declared goods), tax laws, etc.

The analysis helps to clarify the concept of "taxation of tourist activity." So the definition of taxation of tourist activities as "taking in favor of the state and a predetermined portion of the statutory income of the tourist company" greatly expands the list of subjects of taxation (taxpayers) and reduces the number of steps as the tax 
process. A definition of taxes on tourism as "taxes levied on tourists, usually through companies that deal with tourists' focuses only on the support of the tax, which is often associated with indirect taxes.

We have substantiated the following definition: "Taxation of tourist activity - a process of forced and overbearing, irrevocable and grant exemptions in favor of the state and a predetermined portion of the statutory income for enterprises engaged in tourism-specific activity".

Thus takes into account the possibility of not only indirect but also direct taxation. The process of withdrawal involves three main stages: the establishment, collection and payment of taxes and fees.

Principles of taxation of tourist activity standard:

1) Savings: taxes should be simple to operate, so as to minimize the cost of resources. Taxation should not disrupt the tourism system.

2) Fairness: uniform taxation of tourism in relation to other sectors of the economy.

3)Efficiency: To minimize the economic impact of (the tax burden), This implies the development of tax policy, which has minimal effect on the demand for tourism services.

Significant from the point of view of the tax system is the fact that tourist activities are fully applies to small and medium businesses. In Russia in 2010 in the field of hotels and restaurants share of small enterprises was $96.2 \%$, average $-0.6 \%,-3.2 \%$ larger. In tourism, mainly done by women and young people who are most susceptible to social change.

The results of studies of 150 countries show that the tourism industry is labor-intensive.

For more than 80 countries, tourism provides about $10 \%$ of GDP, the same proportion is maintained in exports and employment. Countries with high levels of tourism to GDP, are also the countries with high levels of employment in tourism, and vice versa.

Countries with high GDP per capita have a labor-intensive tourism sector. Relatively poor countries can not be said.

Tourism has its own distinctive characteristics for the purposes of tax modeling as tourism-related goods are consumed as residents of the country, as well as foreign tourists. This feature enables policy-makers to increase tax revenues at relatively low internal social costs than alternative tax policy. The risk associated with such a tax policy is determined by the fact that tourists can replace the consumption of expensive services cheaper, and that a tax increase of goods related to tourism, may adversely affect the domestic consumers or to specific groups of consumers.

Tourism market is a highly competitive market with opportunities consumer choice among several directions (high elasticity of demand). Therefore, this sector is particularly sensitive to tax policy.

As a result, especially tourism activities can be divided into two parts: on the demand side and the supply side.

Taxation of tourist activities related to three features of the tourism industry, as reflected in the theoretical aspects of:

- internalization of external effects from tourists;

- completion of state budget revenues ;

- the cost of production of public goods (eg, higher costs for security due to the involvement of tourists).

The literature on taxation, we can distinguish only a few papers dealing with the taxation of tourism. Note three works: Bird (1992), Forsif and Dwyer (2002), Clark and NJ (1993).

The first and second article is very important in terms of the formation of the concept of taxation of tourism, although they do not have a formalized model. Forsif and Dwyer (2002) show how countries can use market power to extract maximum rents from tourism. Byrd (1992) describes the economic constraints on the way of optimal taxation system tourism and examines fiscal instruments used in developing countries in the field of tourism taxation. Clark and NJ (1993) constructed a model that describes the effect of the tax system on social welfare tourism.

Bird (1992) argues that developing countries tend to be overly tax the tourism sector. In particular, when the country has a special natural conditions and differentiated services and the demand for tourism products is relatively inelastic, there are opportunities to "extract" more tax revenue. Such an increase in taxation can also reduce the degradation of the environment, but the country at risk of loss of foreign exchange earnings from tourism, the demand for tourism product specific country may be more resilient than expected. This, in particular, 
gives rise to a risk in the long term, especially if the uniqueness of a particular place tourism decreases with the accumulation of tourists and is the development of alternative directions.

Empirical studies show different results. Some economists believe that the best tourism develops in domestic taxes, the other points to the efficacy of the import tariff and export subsidy.

Most studies of taxation of tourist activity using partial economic equilibrium model, analyzing the impact of taxes on travel demand .

In the model of general equilibrium analysis of the subjects of tourist activity reveals the microeconomic effects of taxation (the substitution effect and income) and the macroeconomic effects (changes in tourist arrivals).

All studies conclude that the indirect subjects of tourist activity more effectively than other sectors of the economy, and has a positive effect of capital.

In addition, the subjects of tourist activity leads to a better distribution of income, since tourism products are luxuries or consumed by persons with high incomes.

The data presented in the previous section about the labor-intensive tourism sector show that in developing countries will not necessarily improve the distribution of income .

The introduction of a one-time tax on tourist activities in Thailand had a minimal or even negligible impact: real GDP grew by $0,012 \%$, tourism fell by $0,015 \%$, consumer spending tourists decreased by $0.012 \%$, the price of travel has increased by $0,035 \%$, government revenues increased by $0,014 \%$, improved social welfare in the range of $0.001 \%$ to $0.016 \%$. However, with the aviation administration has not decreased.

It is interesting conclusion of China's economists that taxation tourism may even cause it to expand, rather than reduce, if so, the effect of wealth (wealth).

Thus, the taxation of tourist activity goes far beyond the mere collection of revenues to the state budget. Well-developed system of taxation of the tourism industry can benefit residents in several ways. Most or all of the tax burden can be paid by tourists who are not residents of the country in which taxes are levied. On the other hand, taxes on tourism may impose costs on the region in which the taxes are introduced. They can lead to a reduction in economic activity, which is detrimental to GDP, employment and foreign exchange earnings. Decrease in price competitiveness of tourism after the introduction of general or special taxes may reduce the economic contribution of tourism to the economy as a whole. In addition, taxes lead to irretrievable losses, by reducing the welfare of residents: consumers and producers.

\subsection{Characteristics of the Taxation Systems of the Tourism Industry}

The tourism industry is facing a conventional or general taxation of economic activity, as well as a number of specific taxes that affect specifically for tourist activities, but not exclusively.

Among the specific indirect taxes common in developed and developing countries use tax on lodging (hotel-city-tax) (Table 1).

Table 1. Taxes on tourists in hotels (Kanin, 2013)

\begin{tabular}{cc}
\hline Country & Taxes as a\% of total payments \\
\hline Denmark & 25 \\
Iceland & 14 \\
Sweden & 12 \\
France & 5,9 \\
Portugal & 5 \\
Singapore & 4 \\
Switzerland & 3,5 \\
\hline
\end{tabular}

Although there are many supporters of the use of specific indirect taxes on tourism, such proposals tend to cause protest companies that provide services to domestic and international tourism, which consider these taxes as restricting their activities. For example, long-term contracts between tour operators and hotels are a common practice, the new tax can not be added to the price paid by tourists, which leads to lower profits of the hotel. 
In addition, special taxes on tourism are perceived as discriminatory policy that also encourages the practice of tax evasion.

However, at the regional level, the use of specific indirect taxes on tourism loses its appeal. In Spain, the use of environmental taxes and the tax on leased vehicles.

The second option involves the use of tourism tax general indirect taxes.

Within the general tax this sector can be characterized by a higher level, but the high administrative costs make this approach less attractive.

These taxes are generally lower, for example, the rate of value added tax (VAT) is applicable to flights by about $50 \%$ lower than the total tax rate in the 15 old EU member states and $40 \%$ lower than the overall rate of new countries member countries. While tax rates in restaurants, bars and cafes, down $30 \%$ and $20 \%$, respectively.

\subsection{Assessment of the Current System of Taxation of Tourism Activities and Development of Requirements to} establish a Rational System of Taxation

The current tax system is a large number of outstanding issues. For example, on the basis of the current legislation is difficult to determine the place of supply of services in the tourism sector, a Russian entity sells vouchers under an agency agreement with a foreign organization. Subparagraph 3 p. 1 tbsp. 148 of the Tax Code recognizes the place of sale of Russian tourism services, only if they are actually on the territory of the Russian Federation. However, tourism services, as a rule, are complex.

As a result, there is a belief that if under the agency agreement are just tourist services, the place of their implementation of the Russian Federation is recognized (only if the services are actually rendered in the territory of the Russian Federation). If, however, under the agency agreement the Russian organization of tourist services has not, but only engaged in search of tourists and paperwork, rules paragraphs. 3 p. 1 tbsp. 148 of the Tax Code on the treaty does not apply.

Similarly, there is a problem, if vouchers are implemented in the Russian Federation, and services for them are abroad. In the Tax Code does not answer this question. Are the two points of view. According to the first point of view, the fact that the implementation of the permit on the territory of the Russian Federation does not matter, because the more important is the place where the services are actually rendered this tour.

According to the second point of view, the implementation of the permit on the territory of the Russian Federation and is the provision of services for this holiday in Russia. The second point of view is based on the argument that the sale of the permit itself is not a tourist service. And the income a taxpayer receives it from the sale of permits, and not from the provision of services.

Currently, the tax regulation of various businesses in the tourism sector is almost never used, although considered by the state as a priority control services. There is no system of methods of tax regulation of services in tourism, as in the most promising and profitable activity.

\subsection{The Main Directions of the Transformation of Taxation for Tourist Activities}

Transformation of taxation of tourist activity in the Russian Federation is in several ways:

- Improvement of the calculation and payment of certain taxes;

- Improvement of tax administration;

- Improvement of special tax regimes for small businesses;

- Improving the tax regime exclusively for tourist activities.

For example, in 2011, among the measures of improving the value added tax, the most important for tourism activities are:

- The introduction of a new type invoices - corrective invoice;

- Establishment of procedures for the application of VAT in the case of changes in the cost of services after their implementation, including the provision of discounts;

- Clarification of the application of VAT on contracts providing for payment in rubles, the equivalent amount in foreign currency or in conventional units. In these cases, provided the tax base (tax deductions) is not correct, and value differences to take into account non-operating income or as non-operating expenses;

- Clarification of the exemption from taxation of services to provide rental of sports facilities, conduct and training; 
- The establishment of the place of sale in the Russian Federation in the provision of services by foreign persons on the transport between two points within the territory of the Russian Federation (with the exception of services for passengers and luggage, rendered by foreign persons not through a permanent establishment of that person;

- Clarification of the procedure for determining the place of supply for services to provide for the use of aircraft, ships or inland waterway vessels under the lease (chartering at the time) provided by organizations or individual entrepreneurs operating in the territory of the Russian Federation. The place of supply of these services to the territory of the Russian Federation is not recognized if the vessels used for transportation between points located outside the territory of the Russian Federation.

- Simplification of documentary evidence of the legitimacy of applying the zero VAT rate (with the exception of documents confirming the payment);

- Amendment of the list of transactions subject to VAT at the zero rate works (services) related to the transport and shipment of goods transported across the border in Russia, including in the framework of the Customs Union.

Income tax is also to be noted such a measure as the use of a reduced tax rate of income tax for organizations residents of the special economic zone is above $13.5 \%$;

Further improvement of levying income tax due to several trends:

- Clarification of income not taken into account in determining the tax base for income tax;

- Clarification of the procedure for recognizing certain types of costs;

- The possibility of accounting for expenses incurred to a Russian organization of the creation or acquisition of intangible assets, acquisition services, the results of which are used in the activities of organizations in determining the tax base for corporate income tax other interdependent with her organization.

The second trend, primarily due to the simplification of tax accounting. Perfection for the possibility of the use of the taxpayer for the purpose of tax accounting ledgers. Problems associated with the lack of recognition of certain types of expenses and tax preferences.

To solve this problem, it makes sense to bring together the rules of accounting and taxation by making changes in Sec. 25 of the Tax Code. Formally, this can be done by lifting the tax accounting.

The third direction is connected with the improvement of special tax regimes for small businesses. As was shown in Chapter 1 of the dissertation research, tourism sector of the economy stands with a predominance of small businesses. This direction will be discussed in detail in Section 3.3.

We only note that for small businesses and organizations, applying the simplified taxation system, it is expected to reduce the rate of insurance premiums in the state extra-budgetary funds of the Russian Federation in 2014 to $20 \%$.

The fourth line in the Russian Federation is realized by incorporating specific references in the general laws, as shown above.

In our opinion, the transformation must be guided by the following principles:

- Of status - tax law should be taken under the law and under proper democratic control by Parliament;

- Determination of the tax rules;

- Simplicity - tax changes should be simple, understandable and clear;

- It is easy to calculate and simple to collect information, including cost-effectively;

- The right targets - there is no motivation for tax evasion;

- Constant - change the basic rules should be kept to a minimum, the economic rationale changes must be published;

- Consultation - in preparation should involve all stakeholders;

- Regular review to determine relevance;

- Fairness and reasonableness - should be a mechanism for resolving disputes;

- Compliance with the tax transformation objectives of economic development, in particular, investment. 


\subsection{Direction of Forming a Rational System of Taxation of Tourism Activities}

We propose to use in the formation of a rational system of taxation of tourist activity approach based on the concept of marginal excess tax burden.

For the formation of a rational system of taxation is necessary to estimate the difference between the growth of additional revenue and the loss of social welfare benefits from additional tax rates. It is necessary to consider the relationship of the tourism sector with other sectors. Therefore, the final demand is generated from household demand, the state and tourists. (Gubanova \& Kostornichenko, 2014)

In this model, there are two types of links between its indices: 1) technological linkages of economic activities in the process of production, and 2) the relationship, defining (for the economy as a whole) the laws of transformation of certain types of income (wages, profits and taxes etc.) in various types of products, which are elements of final demand. As economic activities have different structure material costs (depending on the production technology), as well as different cost structure of prices of products (characterized by a specific gravity of wages, depreciation, income taxes in the price of products), so the effect of taxation of a single type of economic activity in will generally also different.

The policy against the use of the proposed model involves the use of macroeconomic information on the principles used by the input-output model (table "input-output"). To do this, tourism should be considered as an additional economic activity. Tourism, considered as an economic activity, has a specific cost structure and the structure of the distribution of benefits.

\subsection{Special Tax Regimes as the Direction of Improving the System of Taxation of Tourism Activities}

In other developed countries special and preferential tax system for small and medium-sized enterprises (SMEs) make up the complexity of SMEs in obtaining external funding.

Special tax regimes have become widespread in a number of neighboring countries, such as Armenia, Azerbaijan, Belarus, Ukraine and others. Foreign countries are also used in Brazil, Great Britain, Greece, Hungary, Portugal, USA and others. (Dellaert \& Lindberg, 2003; Stellin, 2010; Litvin et al., 2006; Sheng, 2009; Stellin, 2010; World Tourism Organization, Madrid, 2011; Gago et al., 2009; Dombrovski \& Hodzic, 2010)

Variety of special tax regimes in different countries is largely determined by the difference between the goals that are pursued in the development of such regimes.

For example, such a goal can serve as a reduction of tax evasion. If a developed economy and the tourist resort business, the number of small businesses that provide various services to tourists, can be very large. And when this activity is seasonal in nature and the people who participate in it, and the enterprises themselves after the end of the season may not be available to the tax authorities at a reasonable cost, the introduction of presumptive tax, especially payable in advance allows you to get tax revenues, which, when used general regime did not have the budget.

There are countries where the use of special regimes considered unwise. For example, in New Zealand believe that companies reduce costs associated with compliance with the law, it is possible in other ways.

The use of special tax regimes, as international experience shows, positive effect on the growth rate of business, create new jobs, increase investment, which in turn leads to an increase in the welfare of the population and improve the overall economic climate area.

Advantages for entrepreneurs playing:

- Simplification of the tax administration system due to fewer taxes, a simpler organization and record keeping, reducing paperwork, the application of the cash method of accounting for income and expenses;

- Reduction of the tax burden.

Any special tax regimes distort the allocation of resources (violation of allocate efficiency) and violation of justice.

The main drawback of the UPDF - requirement does not go beyond the criteria of employment and income levels established by the Tax Code. The practice of applying the simplified taxation system for the last five years has shown that these restrictions are a serious obstacle for the booming business.

It is justified would be to increase the amount of marginal revenue in the UPDF, to a wider range of businesses able to use this system, but the taxpayers are already using it, did not experience any discomfort associated with the transition to the general taxation regime with a slight excess of the limit. 
In addition, STS taxpayers should keep track of all changes in tax law, since the introduction of a new tax or tax change of name means automatic inclusion of them as its contributors. Solution to duplicate records of business transactions on the accounting rules or the possible emergence of responsibilities transfer to the payment UTII one or some of the activities may result in an increase in the cost of doing accounting.

Statistics show that the most popular system in the small business abroad is a simplified system of taxation in the form of a patent for individual entrepreneurs, which is a modernized view of the UPDF.

The system of taxation based on the patent - a modernized form of the UPDF.

The essence of this method of taxation is to pay a fixed amount for a patent for a type of business entrepreneur is involved, without involving the activity of employees.

The advantage of this approach, despite the need to observe restrictions on the size of annual revenue, that a list of activities with the possibility of purchasing a patent is so broad that practically covers the entire spectrum of interests of small business. The conditions of work with the purchase of a patent is much easier conditions UPDF.

Since January 1, 2013 will be introduced patent system of taxation for individual entrepreneurs, which as part of the second chapter 26.5 of the Code will be highlighted in Chapter 26.2 "simplified tax system" in an independent special tax regime.

Subjects of the Russian Federation will be required to take the end of 2012 with the introduction of laws on 1 January 2013 in the territories of the patent system of taxation on 47 activities identified in Section 26.5 of the Code. In addition, they will be able to enter this tax regime on the supplementary list of business activities relating to consumer services not specified in Chapter 26.5 of the Code, except for the activities of pawnshops, of passenger rail transport, air transport passenger services, freight transport services, communication services, utilities, cultural institutions, services of tour operator and travel agent, health and wellness services, services provided by notaries public, the services provided by the legal profession, financial intermediation services, insurance services and services in the field of advertising.

Individual entrepreneurs, applying the patent system of taxation, will be permitted to use the employees, the average number of which shall not exceed 15 people.

At the same time $90 \%$ of the proceeds from the patent system of taxation will be sent to the budgets of municipalities and $10 \%$ in the budgets of the Russian Federation.

Analysis of existing systems of taxation of small business has shown that the special tax regimes should certainly contribute to the development of small business in our country, including in the tourism sector. However, they can still be found contentious issues that must be addressed. So in the Tax Code of the Russian Federation has not yet been established that the taxpayer do if he lost the right to use the simplified taxation system for reasons other than those listed in Sec. 4 tbsp. 346.13.

UTII will be canceled from 2018 to the international practice of the analog mode is not. The main thing to aspire to when establishing the special modes are: compliance with the tax burden of business profitability elimination of discriminatory provisions.

Reasons to use UTII and patents in the field of tourism the same: seasonal services. This probably explains the use of such taxes in France, Italy, Spain, Israel, etc.

It seems that in the long term should remain two special tax regime: on the basis of a patent and the UPDF to subject to tax "income minus expenses."

In this case, the first introduced for entrepreneurs without legal entity having no employees and is not providing services to other businesses.

The second applies to for larger enterprises, legal entities and individuals, with employees. This tax is considered to be the closest to the tax on real cash flows, which is neutral to investment decisions and allocate efficiency.

In general, special tax regimes tourist activity should accomplish three main tasks:

1) to counteract market failures, particularly asymmetric information;

2) reverse the drawbacks of small businesses (as the most popular tourism), namely, the disproportionate costs of tax regulation, the asymmetry of the taxable profit or loss;

3) ensuring the survival of business. 
One key element in the mechanism of support and development of small businesses in the service sector is the tax system. The experience of countries with developed market economies suggests that there must be a deliberate program of reforming the tax system, aimed at strengthening and supporting small businesses, including small businesses in the tourism sector.

In general it can be concluded that to improve the competitiveness of small enterprises in the tourism sector should be reduced insurance premiums for them to $21 \%$.

It should be noted that the tourism industry is not limited to the travel agencies - it includes a whole range of organizations. Therefore, the provision of tax incentives to these organizations will have an impact on the tourism sector. (Kryukova et al., 2013; Zaernjuk et al., 2014)

Thus, in our opinion, it is necessary to apply the following measures in the framework of the modernization of the system of taxation of small enterprises in the tourism sector:

1 Introduction of preferential VAT in tourism of $10 \%$, as well as a refund or a refund of the tax, as it is practiced throughout the world. Tourism is one of the priority sectors of the Russian economy, as it is a component of the country's image in the international arena, so it is advisable to revise the rate on value added tax downward.

2 Cancel the profit tax from organizations with museums and a reduction of income tax of hotels up to $18 \%$. This measure is designed to support tourist facilities in Russia and should lead to a reduction in the cost of tourist services and spending the savings on development and advertising.

3 Reduction for small businesses serving the tourism industry (food, cleaning, souvenirs), the rates of income tax to the level of $15 \%$. Given the small share of income tax on profits derived from small enterprises in total tax revenue, which in 2012 did not exceed $2.3 \%$, this reduction will not cause significant damage to the state budget.

\section{Conclusion}

The future impact of tax regimes is difficult to assess, since different factors have different effects on the choice of tourists. However, the price is noted as one of the main factors selection tourists. In addition, increases the sensitivity of the demand for tourism product to a change in price, which is already characterized by a high level of flexibility.

Thus, it can be argued that the increase in taxes and charges on tourists will have a negative correlation with the number of arriving tourists.

It should be noted that the tourism industry is not limited to the travel agencies - it includes a whole range of organizations. Therefore, the provision of tax incentives to these organizations will have an impact on the tourism sector. Therefore, you must use the following measures as part of the modernization of the system of taxation of small enterprises in the tourism sector:

1 Introduction of preferential VAT in tourism of $10 \%$, as well as a refund or a refund of the tax, as it is practiced throughout the world. Tourism is one of the priority sectors of the Russian economy, as it is a component of the country's image in the international arena, so it is advisable to revise the rate on value added tax downward.

2 Cancel the profit tax from organizations with museums and a reduction of income tax of hotels up to $18 \%$. This measure is designed to support tourist facilities in Russia and should lead to a reduction in the cost of tourist services and spending the savings on development and advertising.

3 Reduction for small businesses serving the tourism industry (food, cleaning, souvenirs), the rates of income tax to the level of $15 \%$. Given the small share of income tax on profits derived from small enterprises in total tax revenue, which in 2012 did not exceed 2.3\%, this reduction will not cause significant damage to the state budget.

Taxation is one of the most important tools for improving the competitiveness of small enterprises in the tourism sector and the provision of tax incentives to organizations working in the field of tourism will increase the competitiveness and development of the tourism market in Russia. Thus, the taxation of the tourism industries creates additional tax revenue at a relatively low domestic costs.

\section{References}

Borodin, V. V. (2010). Statistical reports as the basis of economic efficiency of tourism. Managerial Accounting, $2,74-81$.

Dellaert, B., \& Lindberg, K. (2003). Variations in Tourist Price Sensitivity: A Stated Preference Model to Capture the Joint Impact of Differences in Systematic Utility and Response Consistency. Leisure Sciences, 25. http://dx.doi.org/10.1080/01490400306557 
Dombrovski, R., \& Hodzic, S. (2010). Impact of Value Added Tax on Tourism. International Business \& Economics Research Journal, 9(10).

Gago, A., Labandeira, X., Picos, F., \& Rodriguez, M. (2009). Specific and general taxation of tourism activities. Evidence from Spain. Tourism Management, 30.

Gubanova, N. V., \& Kostornichenko, V. N. (2014). Evaluating the effectiveness of the provision of financial assistance from the federal budget of the Russian Federation to budget of the Baikonur. Life Sci J., 11(7), 476-479. Retrieved from http://www.lifesciencesite.com

Kanin, T. I. (2013). Development of a modern system of taxation of tourist activity. Dis. Candidate. ehkon. Sciences. 130c.

Kanin, T. I., \& Kaurova, O. V. (2012). Factors constraining the development of tourism (No. 2). Moscow, service plus.

Karmanova, T. E., Kaurova, O. V., \& Maloletko, A. N. (2012). Tourism statistics. Tourism statistic: Tutorial (Text steam. Rus., Eng., 2nd ed.). (Undergraduate). KNORUS.

Kaurova, O, Maloletko, A., Yumanova, O., Kryukova, E. M., \& Deryabina, A. V. (2014). Modern trends in development of tourism statistics in world and in Russia. Life Science Journal, 11(4).

Kaurova, O., Maloletko, A., \& Yumanova, O. (2013). Cross-country Comparison of Statistical Indicators. Life Sci J., 10(4), 1915-1917. Retrieved from http://www.lifesciencesite.com

Kaurova, O., Maloletko, A., \& Yumanova, O. (2013). Ways to counter retrival of "shadow income" from businesses with fixed assets in hospitality. Middle-East Journal of Scientific Research, 15(5), 757-762.

Kryukova, E. M., Makeeva, D. R., Atamanova, M. A., \& Shadskaja, I. G. (2013). Financial mechanism of housing and utilities infrastructure. Life Science Journal, 10(4), 25.

Lennon, J., Smith, H., Cockerell, N., \& Trew, J. (2008). Managing tourism industry. Best experience of national organizations and agencies on tourism (Text, p. 272). Per. Translated from English. "Group IDT".

Litvin, S., Crotts, J., Blackwell, C., \& Styles, A. (2006). Expenditures of Accommodations Tax Revenue: A South Carolina Study. Journal of Travel Research, 45. http://dx.doi.org/10.1177/0047287506291597

Makarovich, Z. V., Mihajlovna, K. E., Vladimirovna, B. E., \& Ivanovna, C. L. (2014). Study of theoretical approaches banking financial intermediation and directions of its development in Russia and Abroad. World Applied Sciences Journal, 30(12), 1746-1748.

Mihajlovna, K. E., \& Pavlovna, S. A. (2014). Assessment of Efficiency of the Hotel Management by a Russian Company. World Applied Sciences Journal, 30(Management, Economics, Technology \& Tourism), 51-54, 2014

Mihajlovna, K. E., \& Rafikovna, M. D. (2014). Konovalov Elena E. Tourism as Preferred Direction in the Strategy of Substitution of Industry Branches in Mono-Territories of Russian Federation. World Applied Sciences Journal, 30(Management, Economics, Technology \& Tourism), 176-178.

Sheng, L., \& Tsui, Y. (2009). Taxing tourism: Enhancing or reducing welfare. Journal of Sustainable Tourism, 17(5). http://dx.doi.org/10.1080/09669580902855828

Stellin, S. (2010). Taxes and Fees Grow for Air Travelers. New York Times: Itineraries.

Tourism Highlights. (2011). World Tourism Organization, Madrid.

\section{Copyrights}

Copyright for this article is retained by the author(s), with first publication rights granted to the journal.

This is an open-access article distributed under the terms and conditions of the Creative Commons Attribution license (http://creativecommons.org/licenses/by/3.0/). 